\title{
Study on Cultural Conflict and Its Integration in the Process of Merger for Military Academies
}

\author{
Da-yong JIANG ${ }^{1, a,{ }^{*}}$ and Yun BAI ${ }^{2}$ \\ ${ }^{1}$ Equipment Engineering College, Engineering University of CAPF, \\ Xi'an, 710086, P.R China \\ ${ }^{2}$ Miliary Basic Education College, Engineering University of CAPF, \\ Xi'an, 710086, P.R China \\ a'wanghe717@163.com
}

Keywords: Institutional culture, Cultural conflict, Cultural integration, Merger.

\begin{abstract}
With the tide of "military reform", the merger of numerous military academies will be inevitable in the future. This not only can realize reorganization and improvement of the military educational resources so that improve the quality and the scale of institutions obviously, but also be conducive to personnel training, scientific communication, knowledge innovation, and combat effectiveness. Because of different educational philosophy, it will lead to the differences among the organizational culture accumulated, selected and cohesive in the long-term teaching and management activities. The collision, conflict and integration will inevitably occur in the merger process. As an unavoidable problem, it is also an important factor for the smooth operation of institutions after the merger. This paper studied three types of cultural conflict arising from the merger model, and analyzed their roots. On the basis of it, three stages of cultural construction and innovation were put forward including prewarning of cultural conflict, the adaptation and identification of heterogeneous culture and cultural integration.
\end{abstract}

\section{Introduction}

With the deepening of the "military reform", the reform of military academies will soon spread, which may involve some merger and reorganization among institutions. The cultural conflicts and integration channel in this process were worthy to study. As a special organizational culture, military institutional culture is thought as the compound system composed of cultural characteristics with different forms. It had a long-term and stable cultural concept and historical tradition, as well as owned unique military characteristics. Due to existing difference and history continuity among the institutional culture, the merger process will be inevitably accompanied by encounters, confluences, collisions and even conflicts, and the different merger types decided on different cultural conflicts for institutions. It was a strategic need to carry out cultural integration for the merged institutions in order to optimize the allocation of high education resources, rationalize the military management system, improve the overall strength, promote the healthy development, and meet the requirements of new military revolution. 


\section{Cultural Conflict from Different Mode of Institution Merge}

\section{Absorption Merger Model}

The model referred to that the weak institutions are merged into the strong institutions with a larger scale, the more comprehensive academic, the higher reputation and comprehensive ranking in the relative institutions. After the merger, both the teaching subunits and the management functions of the original weak institutions were all absorbed into the corresponding institutions and departments of the relatively strong institutions, and their institutions name, management system and the corresponding external logo were all canceled. A typical case occurred in 2011, when Engineering College of CAPF succeed to promote the only one comprehensive university of CAPF on the basis of the absorption of Xi'an Command College of CAPF, and the latter became a secondary college of the former.

Under the strong-weak absorption mode, with the disappearance of the original organizational structure, the decentralization and reorganization of personnel, the division of professional disciplines, the change of institutions motto, most of the cultural factors such as institutions values, institutions spirit, etc were generally replaced by strong institutional culture. If the cultural replacement had not been carried out to drainage by an effective organizational culture, or the staff were lack of cultural adaptation training after the merger, when staff from the weak institutions were not suited for the task of migration, assessment mechanism, and pressure of promotion, they might begin to become anxiety, even produce a strong sense to identity and reminisce their own organizational culture. They can also counter the invasion of new culture with resisting mentality, and stick to the original organizational culture in the pre-merger and merging process, then negatively accepted or hatred the strong culture after the merger. It was easy to result in inferiority complex, collective aphasia, negative sabotage and brain drain for the disadvantageous groups.

\section{Parallel Merge Mode}

Under this mode, the institutions participating in the merger were on the similar scale and at the equal status, which had complementary for each other in terms of disciplines fields or predominance. After the merger, new unit can implement re-naming and re-making logo, but the symbol of original institutions were cancelled or only used on a small scale. In addition, some overlap specialty was shock up a secondary college, and the characteristic disciplines of the institutions were set as a separate secondary college. For example, Engineering University of Air Force consisted of three sibling colleges in Xi'an region, namely Engineering College of Air Force, Missile College of Air Force and Telecommunications College of Air Force. On the base, a new major university headquarters had been established for unified management.

Because each institution maintained independence in a larger range after the merger, the original organizational structure, disciplines and teachers capital remained unchanged, meanwhile its educational philosophy, values, campus spirit, management system also retained in a certain category, which made the cultural feature of independent institution stretch out for long time. But the result was cultural isolation that mean various cultures can coexistence and independent but lacking of communication for each other. In the short term, although cultural isolation can reduce cultural conflicts and maintain a relatively stable teaching and management 
environment, it easily lead to do it themselves for the institutions so that form a closed and conservative academic environment.

The absence of necessary communication and collaboration were conducive to the integration and implementation of overall strategic objectives, new brand and system design, and culture innovation for the institutions. At the same time, when there were more differences and divergences among the departments, the conflict of culture is wider and the conflicts are more complicated and intense, so the difficulties of conflict resolution are also greater. Over time, the cultural and psychological ties among the members will be broken, and their values and behaviors will become chaotic, which can result in increasing of the likelihood of non-benign conflict and reducing of organizational performance for the merged institutions.

\section{Comprehensive Merger Model}

At present, the most of mergers within PLA institutions was comprehensive merger model, which not only included absorption merger model but also parallel merge mode. For example, the new National Defense University established in 2000 years firstly went through with absorption merger model in which Changsha Technology college absorbed an army Institute in 1978. Based on the original National Defense University, Changsha Politics college of PLA, Artillery college of PLA, and Engineering college of PLA further parallel merged into it through parallel merge mode. After the completion, National Defense University had owned a wide range of disciplines and achieved the win-win co-operation among computer science, aerospace engineering and nuclear technology.

The cultural conflicts with comprehensive merger model were more complicated than the former. On the one hand, it not only contained the cultural conflicts arising from the cultural substitution process in the absorption merger mode, but also included the cultural conflicts arising from the cultural isolation in the parallel merge mode. On the other hand, in the reconstruction process including design of job, adjustment of disciplines, implementation of the new incentive measures, the new institutions name, motto, discipline, the remodeling of institutions philosophy and value, abrogate and screening for original institutions culture, extension, dissemination and identity for new institution culture were all confront with the internal members' resistance because of the conventionality to the old culture. It will result in cultural clashes that came from the differences among the intricate cultural of merged institutions. Therefore, the cultural conflict under the comprehensive merger mode was the most intense and difficult to be reconciled.

\section{Root Cause Analysis of Cultural Conflicts in the Merged Process}

\section{The Inheritance of Culture is the Main Root of Cultural Conflicts}

Institutional culture had been developed and practiced through historical accumulation, selection, and cohesion by the common institutions members. In the long-term development process, it became the marrow through continuous adjustment and sublimation of several generations. At the same time, institutional culture was integrated into each link of education, teaching and management activities, and distributed in each corner of the campus, then continuously permeated to form a strong atmosphere and cultural environment. For example, "LI JIAN" culture advocated by Engineering University of Rocket Force was more persistent, stable and inherited than other organizational cultures for their staff. From another point of view, the inheritance and stability was the strong exclusion of other institutional culture. 
When the institutions with heterogeneous cultural began to implement the merger, the exclusion had the feature with resisting and denying the "heterogeneous cultures", while sticking and blind obeying the "Own Culture".

At the same time, the specificity for educational objects, synchronization between teaching objectives and force requirements, and the service of scientific research and logistics management, these factors linked Institutional and troops inextricably. The institutions were more open than other organizations because the various military cultures were integrated into institutional culture, which increased its complexity. The complexity of institutional culture made the cultural conflict of different merge model more complicated and increased the difficulty of cultural integration.

\section{Official Leadership Behavior in the Merger was the Institutional Reasons for Cultural Conflicts}

The merger of military Institutions generally went through thus development process from the adjustment and reform of the structure and organization to the substantive integration. The headquarters or branches of the military used to be led the adjustment and reform of the structure and organization, which was achieved through exercise administrative power. The original system was disrupted on a large scale through a command in a short time, so the educational resources of institutions will make up a new reorganization to achieve concentration and restructuring of power. This rapid merger usually ignored the necessary pre-survey and analysis for cultural integration that was thought of stable, complex and historical integration. This did not make the hidden dilemma of cultural conflict in the institutions get the necessary early warning and control in the beginning of the merger.

\section{The long-term Influence of Cultural Conflict in the Merger of Made Its Consequences Difficult to Quantify and Show}

As an important organization, institutions bearded some responsibility of cultivating, scientific research and technological innovation. The military value created by them was unable to be measured and calculated. As the saying goes, "ten years of trees, a hundred years of people," the long-term of educational effect has also increased such evaluation difficulty for the institutions.

Firstly, cultural conflicts can easily lead to mistrust in the cooperation and uncertainties for the members, which greatly enhanced their attention to personal affairs in the future while reducing the work efficiency. It even resulted in the loss of talent. Secondly, cultural conflict will directly make the institutions staff lack of identity and professionalism after the merger, and ultimately it will bring the quality of education to reduce, the core values of members to dissociate, and cultural chaos that caused the spirit of institutions to disorder. These were detrimental to the creation of the value for institutions, while this damage in a relatively short period of time was difficult to display and evaluate. Therefore, the integration of the merged institutions was easy to be overlooked by the parties, so that the conflict of the merged institutions can not be timely curbed, reducing the effectiveness of mergers.

\section{The Integration of Institutions of Cultural Integration Ideas}

This paper argues that in any merger mode, the cultural integration should include three stages, awareness and prewarning of cultural conflict in the early stage of merger, cultural identity and integration in the intermediate stage of merger, and cultural construction and innovation in the late stage of merger. 


\section{Awareness and Prewarning of Cultural Conflict in the Early Stage}

In the early stage of the merger, the Merger and Integration Group composed by leaders of the institutions, relevant business departments and experts or professors was be founded for the merger. The group shall collect the educational philosophy, core values, organizational structure and participating parties system, incentives for staff, teaching spirit, research management, and the spirit of the campus ion. Through sorting out the similarities and differences in cultural factors, it was responsible to take place communication and exchange with open, equal and frank, so that a comprehensive and true understanding of the cultural characteristics can reach for the merger parties. Through compiling the characteristics of institutional culture into books, and issuing to the teachers and students, the group can make them get a wider realization and understanding. On the basis of this, the cultural conflicts that may occur in the merger process were collected and sorted further. According to the sequencing results, the cultural conflict with large frequency or big influence will be live demo. The early warning scheme and the countermeasure were put forward and designed too. By the mutual understanding, it can reduce the cultural isolation caused by the lack of cultural cognition or error. Applying prewarning mechanism of the culture conflict can effectively prevent the merger risks and make the cultural conflicts in the controllable range.

\section{Cultural Adaptation and Recognition in the Intermediate Stage}

Although the merger parties had a preliminary understanding on culture for each other in the early stage of merger, but the cultural collision was inevitable in the process of integration because culture had a strong historical continuity and the slowness of change, so the integration between two or more cultures needed to go through a certain run-in period. Therefore, the focus of cultural integration in this stage was to promote the adaptability of numbers when facing a variety of cultural coexistence or a strong cultural incursion, to enhance the cultural identity of merged institutions. Due to changes of the cultural environment, psychological principles should be used to alleviate the psychological pressure for members, especially the vulnerable members. Only in this way, it can finish cultivation open-mindedness with inclusive and psychological quality with tolerance and peace, and then achieve the quality leap and optimization for personnel structure and mental model.

\section{Cultural Co-construction and Innovation in the Late Stage}

In the process of creation of knowledge, institutions had been creating their own culture at the same time. In order to following aim, such as promoting the substantial integration, improving the cohesion of each member, and realizing the optimization merging effect like $1+1>2$, joint development and innovation were the focus of cultural integration for merged institutions on the basis of cultural abrogate.

\section{Conclusion}

The co-construction and innovation of the merged institutions culture had gone through four stages: cultural sublimation, cultural integration, cultural innovation and the new culture communication. First, it is the key for cultural sublimation to carry out effective cultural integration by treating the culture of institutions and dealing with cultural conflicts in combination in a scientific and rational manner. Secondly, on the basis of cultural sublimation, the mutual penetration and complementation within the total culture was the integration core. Thirdly, cultural co-construction and 
innovation was not the simple adaptation and superposition of the original cultures, and the new institutional culture needed to be remodeled and innovated according to the new environment. The creation of a new culture required a clear combination of the core values, philosophy, management style and social responsibility of the institutions, and made the original coexistence of various cultures concentrated as a new cultural bundle by giving its new cultural essence, then eliminated the various cultures coexistence derived from the cultural conflict and cultural chaos, so that promoted the cohesion of the institutions and the improvement of the centripetal force. Fourth, the new culture communication needed the integration and re-engineering of the merged institutions which was based on the advocacy of minority and the successful participation of majority. Therefore, the spread and promotion of new culture was conducive to be popularized and reduce the promote resistance. Only when the new institutional culture enjoyed popular support as subconscious for the members, substantive integration can realize from the inside and outside, from top to bottom.

\section{Acknowledgement}

This research was financially supported by the Military Theory Foundation belonging to Engineering University of CAPF (NO. JLK2016-03).

\section{References}

[1] Zhi-ming Xie. Cultural Conflict and Its Integration Strategy in the Merger of Chinese Universities. Economist, 2006, (12): 95-96.

[2] Xu-dong Chai. On the Integration of Organizational Culture in Merged Universities in China. Techniques in Higher Education, 2008, 27 (5): 5-8.

[3] An-min Li. On the Culture Assimilation Pattern in M \& A Integration. Academic Research, 2003, (11): 23-26.

[4] De-qun Li. Cultural Conflict and Cultural Construction in Consolidated Universities. Heilongjiang Higher Education, 2010, (4): 84-86. 